


\title{
ESTRATÉGIAS DE COMUNICAÇÃO EM SITUAÇÃO POLIÁDICA DE CRECHE
}

\author{
EULINA DA ROCHA LORDELO
}

Universidade Federal da Bahia

\author{
ANA MARIA ALMEIDA CARVALHO
}

Universidade de São Paulo

\begin{abstract}
RESUMO
Tendo em vista a importância das experiências iniciais, em termos de responsividade e sincronicidade nas interações com o meio, com amplas repercussões nos terrenos cognitivo, sociale afetivo, o presente trabalho objetivou investigar as possibilidades da creche como contexto interacional. 62 crianças de um a três anos, de cinco creches diferentes, metade delas proveniente de creches privadas e as demais de creches públicas, foram observadas em seus ambientes naturais de brinquedo, nas creches, em três sessões de dez minutos cada, tomadas em dias diferentes. Amostras de episódios interativos entre adultos e crianças foram examinados qualitativamente, buscando identificar os parceiros das interações e os modos pelos quais criança e adultos situam-se no conjunto das interaçôes. Os resultados dessa análise sugeriram que o adulto, além das esperadas estratégias de comunicação individual ou coletiva, emprega comumente uma terceira estratégia básica de comunicação, aqui denominada comunicação articulada, com alternância de alvos e articulação, inclusive temática, entre os alvos. Nesse padrão, o adulto estende as interações que ocorrem com um indivíduo para outros, amplificando o episódio interativo, criando inter-relaçôes entre temas e indivíduos. Esses resultados são discutidos em termos da inadequação da oposição situação diádica versus poliádica, que costuma ser empregada para comparar os contextos de criação em ambientes familiar ou coletivo.

INTERAÇÃOSOCIAL — RELAÇÃOADULTO-CRIANÇA - CRECHES - DESENVOLVIMENTO SOCIAL - CRIANÇAS
\end{abstract}

\section{ABSTRACT}

STRATEGIESFORCOMMUNICATING IN POLNALENTSITUATIONSATDAY CARE. Consideringthe importance of early experiences, particularly regarding responsiveness and synchrony in the interactions with the environment, with important effects on the cognitive, affective and social areas, this study aimed to search the day-carecenters possibilities as interactional contexts. 62 children aged I to 3 years old, from 5 different day-care centers, half of them from private and the others from public day-care centers, were observed at their natural play settings, in three sessions of 10 minutes each, obtained in different days. Samples of interactive episodes between adults and children were qualitatively examined, aiming to identify the interactional partners and the ways through which children and adults set themselves in the whole interactional pattern. The results of this analysis suggest that the adult, besides the expected strategies of individual and collective communication, use ordinarily a third basic communication strategy, called articuled communication, with thematic and other forms of alternation between the targets. In this pattern, the adult extends the interactions that occur with an individual to others, amplifying the interactive episode, creating links between themes and individuals. These results are discussed in terms of the inadequacy of the opposition between dyadic versus polyadic situations, that is generally used to compare the rearing contexts in family and collective environments.

Este trabalho foi elaborado usando-se parte dos resultados da pesquisa desenvolvida pela primeira autora, apresentados em sua tese de doutorado Ambiente de Desenvolvimento Humano: uma reflexão a partir do contexto creche, sob orientação da segunda autora, no Instituto de Psicologia da USP, em 1995. 
O contexto interacional da creche, limitado pela pequena disponibilidade de adultos para interação diádica' com a criança, constitui um importante problema de investigação, na medida em que, aparentemente, viola a configuração da díade adulto criança como contexto mais adequado para o desenvolvimento nos primeiros anos de vida.

O papel do adulto recebe destaque em várias abordagens, notadamente no campo do cognitivismo piagetiano, com sua tradicional ênfase sobre o egocentrismo pré-operacional da criança e a decorrente incapacidade de interações complexas, pela dificuldade de assumir a perspectiva do outro, e nos enfoques etológicos sobre o ambiente de desenvolvimento, em que se sugere o ambiente de alguns adultos conhecidos e umas poucas crianças de idade diferentes como arranjo ideal para o desenvolvimento da criança (Konner, 1976; Bowlby, 1984).

Também a pesquisa mais recente sobre mecanismos de desenvolvimento aponta para a evidência de que as trocas iniciais da criança com o meio requerem condições muito favoráveis, em que o adulto ajusta o ambiente às limitações do bebê, fornecendo o necessário suporte ao comportamento da criança (Papousek, Papousek, 1984). Essas estratégias de ajuste, utilizadas sem planejamento consciente, são possíveis graças à capacidade do adulto de reconhecer estados comportamentais dos bebês, incluindo emoções e estados de necessidades (Kostermann, apud Papousek, Papousek, 1984; Bergamasco, 1992).

A partir dessa classe de dados, Papousek, Papousek (1984) hipotetizam um sistema educativo natural ideal representado na interação pais-filhos, requerendo a forma de trocas diádicas - apenas uma dupla por vez. Tal sistema afetaria o desenvolvimento cognitivo da criança, relacionado ao tipo de estimulação maternal.

As características mais marcantes do ambiente de apoio incluiriam, da parte do adulto: o estilo da comunicação oral, caracterizado pelo uso da fala maternal (baby talk ou motherese) e o ajustamento ao estado comportamental do bebê; também as estratégias de encorajar o bebê a observar o ambiente e a tendência a exibir padrões de comportamento simples e repetitivos, tornando-os contingentes a comportamentos do bebê, fariam parte das habilidades comuns dos adultos, freqüentemente não planejadas e inconscientes. $\bigcirc$ uso dessas estratégias possibilitaria à criança conceitualização, predição e manipulação do cuidado recebido.

Corroborando a importância da responsividade do ambiente proporcionada pelo adulto no desenvolvimento inicial da criança, encontram-se estudos sobre a correlação entre personalidade e estilos de interação maternos e o desenvolvimento de apego seguro na criança (Weininger, 1983, Pederson et al., 1990; Isabella, Belsky, 1991). Estudos mais recentes fornecem evidências mais consistentes sobre os efeitos da qualidade do ambiente inicial fornecido pela mãe no desenvolvimento da criança são favorecidas aquelas crianças que vivenciam experiências de maior responsividade materna. Por exemplo, Seiner, Gelfand ( 1995) encon-

I. Os termos diádico e poliádico, correntes na literatura sobre interação, referem-se ao número de parceiros em interação: diádico, a duas pessoas, e poliádico, a mais de duas pessoas. 
traram efeitos negativos no comportamento de crianças expostas a curtos episódios de retraimento e depressão maternos simulados.

O papel do adulto como parceiro da criança é também destacado em Schaffer ( 1992), que aponta os episódios de envolvimento conjunto - EECs - como o contexto básico do desenvolvimento, promotores da mudança desenvolvimental. Num EEC, tipicamente a criança focaliza algum objeto de seu interesse e vai até o adulto, geralmente a mãe, quando encontra algo interessante ou alguma dificuldade. A mãe responde imediatamente, faz uma pausa para identificar o tópico de interesse da criança e então fornece o que for necessário: ajuda, apoio, informação, idéias adicionais, tom emocional, etc. Esse tipo de evento, de duração aproximada entre vinte e quarenta segundos, ocorre dezenas de vezes durante um dia e parece ser o centro das situações de ensino envolvidas na promoção do desenvolvimento. Essa hipótese recebe apoio de alguns estudos que encontraram um melhor desempenho da criança em diversas atividades, como uso de brinquedo e realização de tarefas quando a mãe se engaja em estratégias estruturadas de assistência à criança, numa atuação responsiva e sincrônica (Belsky, Goode, Most, 1980; Slade, 1987; Freund, 1990; Landry et al., 1996).

Embora reconheça que os EECs podem ocorrer entre mais de duas pessoas, Schaffer restringe o campo de estudo à situação diádica, tendo em vista a evidência do reduzido potencial de responsividade interativa na situação poliádica. Essa particularidade torna esse tipo de evento especialmente interessante como uma situação teste para investigar as possibilidades da creche.

No mundo moderno das grandes cidades e de famílias cada vez menores, o recurso à creche como modo de criação, embora venha se constituindo no arranjo padrão, não é adotado sem discussão. A literatura nacional vem destacando o caráter assistencial da creche, com a conseqüente ausência de uma política pedagógica para o setor, o descaso do Estado em prover o que deveria ser um direito do cidadão, como fatores limitantes à busca de soluções para o atendimento de qualidade à criança de zero a seis anos (Oliveira, Ferreira, 1986; Rosemberg, 1989; Rosemberg, Campos, 1994). Ainda que algumas dessas visões distorcidas estejam em processo de mudança, restam muitas questões controvertidas vinculadas à natureza da creche, centradas basicamente sobre os efeitos presentes e futuros da experiência de creche para a criança. Assim, perturbações na formação dos vínculos de apego, efeitos na formação e desenvolvimento de habilidades interpessoais, o impacto no desenvolvimento cognitivo e suas repercussões nos anos escolares, são aspectos que vêm merecendo investigação empírica. Não obstante os dados muitas vezes inconclusivos, alguns resultados consistentes vêm apontando ou ausência de efeitos (positivos ou negativos) da experiência de creche, ou uns poucos efeitos positivos para crianças de baixo nível socioeconômico, apenas em atendimentos de alta qualidade (Scarr, 1993).

Independentemente dos resultados da pesquisa sobre efeitos da creche, a sua inevitabilidade no mundo de hoje aponta a urgência de conhecimentos que fundamentem a busca da melhor qualidade possível, derivada das complexas decisões que são necessárias no 
dia-a-dia e que podem afetar o bem-estar da criança, no presente e no futuro. A compreensão das características do contexto creche, na dimensão das interações entre adulto e criança e entre essas interações, deve ser um dos aspectos de maior impacto social na área de criação e educação de crianças pequenas. Tal preocupação pode direcionar a pesquisa para a busca de soluções práticas e imediatas para objetivos sociais relevantes, como apontado por Rossetti-Ferreira (1994; 1995).

Assim, este trabalho propôs-se a caracterizar a ocorrência de interação na situação de creche e examinar as estratégias empregadas pelos participantes em uma situação típica de ambientes coletivos, com implicações para o contexto interativo, na dimensão diádica versus poliádica. $\bigcirc$ principal problema focalizado foi o dos agentes constituintes das interações. Buscou-se esclarecer a viabilidade de o adulto constituir-se num parceiro do desenvolvimento da criança, numa situação em que o número de crianças por adulto é, por definição, incompatível com a responsividade requerida para as interações diádicas, expressa em sintonia e sincronia entre os membros da díade.

Este objetivo ganha relevância na medida em que os dados resultantes podem contribuir para esclarecer os processos de interação entre adultos e crianças, a natureza de suporte das intervenções adultas, o papel da responsividade do ambiente e os efeitos da exposição a diferentes experiências no desenvolvimento humano.

Especificamente, a análise visou identificar as oportunidades de trocas sociais na situação de creche, em termos de variabilidade e complexidade possíveis e as estratégias que são adotadas pelos participantes para lidar com essa situação particular. Como decorrência desse objetivo, foi também examinada a possibilidade de tais seqüências ocorrerem sem a necessidade de uma díade sincrônica em interação, de cada vez, podendo se dar em situação de grupo. Pretendeu-se ainda identificar as diferentes estratégias usadas pelo adulto no contato com a criança na situação de grupo e a responsividade da criança a essas estratégias.

\section{MÉTODO}

Amostras de episódios de brinquedo livre em creche foram retiradas de um conjunto de dados de observação de 62 crianças de um a três anos, em situação de brinquedo livre, sendo trinta crianças de creches privadas e as demais de creches públicas. As crianças foram filmadas em três sessões de dez minutos cada, em dias diferentes, após familiarização com equipamento e observador. A filmagem acompanhou uma criança por vez, procurando incluir os alvos da atenção da criança, tanto objetos como pessoas, outras crianças ou adultos.

Todas as sessões foram transcritas com o máximo de detalhes permitido pela distância de filmagem, incluindo: a) ações da criança focal e ações do adulto dirigidas àquela; b) alvo da ação da criança; c) trocas verbais; d) informação da movimentação corporal e expressão facial e e) contexto da ação. A transcrição manteve as seqüências temporais e os encadeamentos de ações. 


\section{RESULTADOS}

Estratégias do adulto

Os trechos a seguir apresentam alguns exemplos de situações em que adultos interagem com crianças em diversos contextos:

\section{Primeiro trecho}

Por sugestão de $\operatorname{Nara}^{2}$ (2. I I ), BIA e aproximadamente dez crianças (com idade variando de dois a quatro anos) resolveram brincar de "cabaninha". A cabana é um conjunto de pilhas de pneus velhos cobertas por um pano. Os pneus foram reunidos por BIA e por várias crianças. O pano foi trazido por BIA. O trecho recortado abaixo tem início quando a cabana está quase pronta. A fantasia de bruxa já estava sendo usada por várias crianças, uma de cada vez, antes do começo do episódio, e o modo como foi incorporadaà brincadeira da cabaninha, até onde se pode perceber, nãofoi planejado pela educadora.

\section{Márcio (2.9) Creche privada}

Márcio está sentado em um pneu. BIA diz: "Levante, Márcio!". Márcio levanta e anda. BIA pede às crianças para irem buscar mais pneus (ela usa um tom excitado, lúdico). Márcio e outras crianças correm em direção aos pneus. Várias crianças trazem pneus, mas Márcio volta sem nada, aproxima-se da cabana. BIA: "Peraí, peraí, pra não derrubar os pneus". Chama uma criança e diz: "Aqui, ó, pra não derrubar". Márcio olha (participa mais observando, engaja-se pouco). BIA: "Na cabana não dá pra ficar de pé". Márcio olha, abaixa-se, olha dentro da cabana. BIA continua dando instruções sobre não ficar em pé na cabana: "Não pode ficar mexendo aqui em cima também". Márcio olha a cabana. BIA: "Lembre que não é uma cabana de tijolo, nem de palha, nem de madeira (referência a Os três porquinhos)". Márcio olha (espera a arrumação do pano). (...) BIA começa a falar do lobo: "É o lobo, quem vai ser o lobo?". Márcio fala: "O lobo, o lobo!", olhando para uma criança. (...) Márcio olha a criança com a máscara, sorri e fala: "Bruxa!", Aproxima-se da "bruxa”, sorri, olha, fala algo com a bruxa. Márcio olha alternadamente para a bruxa e o carrinho. BIA está perto, emite sons de medo, incita as crianças a se esconderem da bruxa/lobo. (BIA fornece dicas para o "enredo" da brincadeira para o grupo e destaca uma ou outra criança individualmente para comentários e incitamentos). A "bruxa" começa a entrar na cabana. BIA: "Dona Bruxa, dona Bruxa, não pode entrar na cabana". A "bruxa" recua de costas, tropeça em Márcio, Márcio cai sentado, olhaa "bruxa", começaa empurraro caminho, afasta-se.

\section{Segundo trecho}

Mira (2.7) - Creche pública

Excerto 1

Mira está em pé junto a uma mesa, com Breno André (2.4), Breno Santos (2. I 0) e Júlia (2. I I ) (...). Mira grita, corre em direção à uma mesa, onde SÍLVIA está mexendo em gravuras. Breno André

2. Todos os nomes são fictícios. Os nomes dos adultos estão grafados em letras maiúsculas e os das crianças em minúsculas. 
emite um ruído semelhante ao grito de Mira e encosta na mesa ao seu lado. (...) Lana (2. I ) também se aproxima da mesa. Breno André e Mira olham uma gravura. SÍLVIA aponta para a gravura e fala: "O que é isso?" Mira fala algo e SÍLVIA pergunta: "O quê?" Mira fala algo. SÍLVIA pergunta: "Quando?" Mira responde, olhando SÍLVIA. SÍLVIA diz: "É um parque! É um parque mesmo!", sorrindo e balançando a cabeça, aprovativamente. Mira também balança a cabeça afirmativamente. SÍLVIA repete várias vezes o gesto e a fala: “Um parque!” Mira fala. SÍLVIA diz: "Você foi de manhã? No parque? Você brincou disso aqui tudo?" Mira responde. SÍLVIA olha Mira (expressão atenta, interessada). Mira vira de costas para SílVIA, anda para um outro lado da mesa; Breno André encosta no lugar ocupado por Mira e fala, olhando SÍLVIA. SÍLVIA começa a falar com Breno André, pergunta: "O que é isso?" Breno André responde. SÍLVIA fala: "Hã?", inclinando o rosto para frente. Breno André responde, olhando alternadamente para SíLVIA e a gravura. SílVIA pergunta, olhando Breno André: "Como é o nome disso? Vocêjá viu um desse?" Mira aproxima-se e olha a gravura. SÍlVIA fala com Breno André e diz: "Uma vaca!". SÍLVIAe Breno André falam, apontando a gravura. (...) Mira diz: "Uma vaca!". SÍLVIA olha Mira e confirma: "Uma vaca. ", balançando a cabeça. Júlia e Lana aproximam-se. SílVIA confirma várias vezes: "Uma vaca, é uma vaca" (...)

\section{Excerto 2}

SÍLVIA, de cabeça baixa, sem olhar para qualquer criança em particular, pergunta: "E aqui em cima, o que é?" Lino, na extremidade da mesa, distante um pouco de SÍLVIA, responde: "É areia, é areia, é areia!". SÍLVIA olha Lino, sorri, com as sobrancelhas arqueadas e diz: "Ééé". Mira diz, olhando Lino: "Areia". SÍLVIA olha Mira e diz: "É areia".

\section{Excerto 3}

SÍLVIA fala, olhando primeiro para Breno André e depois para Mira: "Essa menina está tomando café. A menina está sentada, bonitinha, na mesa, pra tomar a merenda, o café, o almoço, não é? Tem que sentar assim, na cadeira". Mira balança a cabeça, afirmativamente, pergunta algo. SÍLVIA responde a Mira: "Na cadeira, sentado na cadeira, bonitinho". SÍlVIAfaz mímica de beber e comer. Mira repete os gestos, inclinando a cabeça para trás, dizendo: "Assim?" SÍLVIA repete o gesto na inclinação "correta", dizendo que não se deve virar a cabeça para trás. SílVIA diz, sorrindo: "Isso, assim!", quando as crianças repetem o gesto "corretamente" Breno Santos começa a tossir. SÍLVIA mostra que se deve por a mão na boca. Breno Santos tosse, pondo a mão na boca. SílVIA põe a mão na frente da sua boca. Breno André faz o mesmo. SílVIA olha Breno André, mantendo a mão sobre a boca, balança a cabeça confirmando. (...)

\section{Excerto 4}

SÍLVIA olha Mira, ergue as sobrancelhas, com expressão surpresa, de interesse e diz: "Sua mãe viu isso? Você viu também?" Mira balança a cabeça afirmativamente. Mira fala algo. SílVIA diz: "Ele foi atrás de quê, o bicho?" Mira responde algo. Enquanto isso, as crianças mexem nas gravuras. SíLVIA 
pergunta: "O bicho foi atrás de sua mãe? E fez o quê com ela?". SílVIA pergunta: "Ah, ela foi o quê? Visitar o bicho?". Mira diz: "É". Breno Santos olha Mira. SÍLVIA fala: "Essa história de bicho tá muito mal contada". (...).

\section{Excerto 5}

SÍLVIA diz: "... cabelo, cabelo”. Breno Santos fala, olhando SÍLVIA. SÍLVIA olha Breno Santos. Mira olha Breno Santos. SÍLVIA fala com Breno: "Na cabeça dele tem o quê?". Uma das crianças responde: "Piolho!". SÍLVIA faz uma expressão de nojo, inclina o corpo para trás e diz: "Ave Maria! Lá vem, na cabeça de todo mundo tem piolho". Breno Santos diz: "Eu tenho". SílLVIA pergunta, olhando Breno Santos: "Você tem piolho?" Ele confirma, balançando a cabeça. SÍLVIA: “...eu não gosto nem de ouvir falar dessa palavra, piolho? Ec!".(...)

\section{Excerto 6}

Mira puxa uma gravura para si. Breno André bate a mão na mão de Mira e puxa a gravura, dizendo: "Não!". SÍlVIA fala: "Ô, Breno, mas não pode bater!".(..)

Como se vê nas partes em negrito no primeiro trecho, a educadora participa ativamente da atividade das crianças: I) definindo e comandando tarefas (BIA pede às crianças para irem buscar mais pneus); 2) corrigindo a ação das crianças (BIA: "Peraí, peraí, pra não derrubar os pneus". Chama uma criança e diz: "Aqui, ó, pra não derrubar"); 3) explicitando limites do ambiente físico (BIA: "Na cabana não dá pra ficar de pé"); 4) estabelecendo relações entre a atividade atual e experiências e aprendizagens passadas (BIA: "Lembre que não é uma cabana de tijolo, nem de palha, nem de madeira); 5) apontando necessidades de estruturação da brincadeira (BIA começa a falar do lobo: "É o lobo, quem vai ser o lobo?"): 6) oferecendo encorajamento e tom emocional (BIA está perto, emite sons de medo, incita as crianças a esconderem-se da bruxa/lobo); 7) estabelecendo regras para a atividade (BIA: "Dona bruxa, Dona bruxa, não pode entrar na cabana!").

Outros modos de participação que podem ser vistos no segundo trecho são: 8) delimitação de um tópico específico para trocas, dentro de uma área de interesse maior (SÍLVIA aponta para a gravura e fala: "O que é isso?"; 9) requerimento de explicitação e clarificação ("O quê?". "Quando?"); I0) audiência reforçadora (SÍLVIA: "Um parque!", sorrindo e balançando a cabeça, aprovativamente); I I) fornecimento de informação (Ela diz: "Uma vaca!"); 12) fornecimento de modelos de conduta, regras culturais (SÍLVIA fala, olhando para Mira: "A menina está sentada, bonitinha, na mesa, pra tomar a merenda, o café, o almoço, não é?"; SÍLVIA repete o gesto na inclinação "correta", dizendo que não se deve virar a cabeça para trás); 13) fornecimento de contingência quanto à natureza imaginária da elaboração da criança — a 
idéia de real versus imaginário, falso versus verdadeiro (SÍLVIA fala: "Essa história de bicho tá muito mal contada"); I4) atribuição de valor a objetos e temas (SÍLVIA: “...eu não gosto nem de ouvir falar dessa palavra, piolho? Ec!"); 15) condenação e expressão de regra de conduta associada à condenação (SÍLVIA fala: "Ô, Breno, mas não pode bater").

Os exemplos mostrados acima afirmam a riqueza das interações possíveis na situação de creche. Em dois trechos de menos de quinze minutos cada, podem ser encontradas quinze formas de participação do adulto, não planejadas, na atividade da criança. Eles atestam também a viabilidade das interações diádicas em grupo, em que a seqüência da interação com uma díade é interrompida para iniciar ou continuar uma seqüência com outra díade. Mais do que isso, vários trechos apontam para a interação do grupo como um conjunto articulado de parceiros. Isso quer dizer que a mudança de foco do adulto de uma para outra criança não é uma verdadeira interrupção, no sentido de ruptura, uma vez que a interação atual com uma criança está relacionada com a interação precedente com outra criança e, algumas vezes, com a mesma criança num momento anterior. $\bigcirc$ grupo funciona como um conjunto em que cada criança assume, em algum momento, um lugar privilegiado na interação com o adulto, sem exclusão das demais.

Os exemplos apresentados evidenciam também a existência de três estratégias básicas empregadas pelo adulto no contato com a criança, a saber: I) comunicação coletiva, sem individualização; 2) comunicação individualizada; 3) comunicação com vários indivíduos, com alternação do alvo e articulação entre os vários alvos.

\section{Comunicação coletiva}

Nessa primeira estratégia, o adulto dirige-se a várias crianças ao mesmo tempo e a ninguém em particular. Esse tipo de estratégia é empregado em certos momentos no curso das atividades, mais comumente quando se trata de realizar rotinas, ou quando o adulto propõe uma nova atividade, rearrumando o conjunto do ambiente. Amostras dessa estratégia podem ser vistas nos trechos abaixo, nas partes em negrito:

\section{Terceiro trecho}

\section{Breno André (2.4) — Creche pública}

Breno André está andando entre as crianças, olhando. GAL fala da porta: "Bora, crianças? Na fila!" Breno olha rapidamente na direção de GAL, olha Breno Santos (2. I0) e Pedro (2.3), anda na direção de GAL.

\section{Quarto trecho}

Nara (2. / I) - Creche privada

As crianças estão numa roda (seis a oito) junto com mais duas educadoras, brincando de "passar a bola". Nara estivera durante todo o tempo junto à roda, sentada, sem participar da brincadeira. Após 
várias "rodadas", há uma certa dispersão (uma criança levanta, outra deixa a bola passar sem pegá-la. Camila (mais de 3 anos), ao lado de Nara, oferece-lhe a bola. Nara afasta o corpo. Camila dá a bola a BIA. Nara observa. BIA pergunta: "Vamos brincar ainda de 'levar a bola' ou querem brincar de outra coisa?" Nara responde prontamente: "De outra coisa!". BIA: "De outra coisa o quê, Nara?”. Nara: "De rolo" (?). BIA: "Daquele rolo?". Nara balança a cabeça afirmativamente. BIA sorri e fala (baixo). ISA fala com Nara: "Depois do lanche a gente brinca com o rolo. BIA: "Vamos brincar de pega-pega"... Vamos brincar de pega-pega". As outras crianças levantam, Nara permanece sentada no colo de BIA. BIA fala com alguém. Nara levanta. BIA pergunta: "Vai ser o quê?" NaraolhaBIAeumacriançadiz: "Lanche!" BIA: "Não, émuito cedo paraolanche!" Narafala: "Esconde-esconde!"

Nas partes em negrito, observa-se o padrão em que o adulto dirige-se ao grupo como um todo, sem especificar um indivíduo. No primeiro trecho ("Bora, crianças? Na fila!'), trata-se de estabelecer ordem ou disciplina típicas de grupo, enquanto nos dois últimos, o adulto verifica a disposição do grupo para mudança de atividade. Nesse trecho, o grupo focalizado é pequeno e relativamente fluido, porque a disposição espacial das pessoas não é circunscrita por limites físicos e/ou sociais rígidos, enquanto no primeiro caso, o comando é dado para a classe como um todo.

\section{Comunicação individual}

Nessa segunda estratégia de comunicação, o adulto focaliza uma criança de cada vez e entra em contato com ela, com variadas funções. Como a situação de creche implica a presença, ao mesmo tempo, de muitas crianças num espaço delimitado, o uso dessa estratégia é limitado a períodos pequenos. $\bigcirc$ adulto alterna sua atenção entre várias crianças, de forma independente, conforme veremos nos trechos a seguir:

\section{Quinto trecho}

Nara (2. / I) - Creche privada

Nara pega objetos e entrega-os, um a um, a BIA, que os vai arrumando ao lado. BIA acompanha continuamente a atividade de Nara, pega areia, põe dentro de pequenos vasos. Nara senta ao lado de BIA. Lúcio (2.I I ) fica encostado em BIA, mexendo nos cabelos dela. BIA olha para Lúcio, sorri. BIA volta atenção para atividade de Nara, fala sobre o brinquedo e mexe nos vasos. Nara olha a atividade de BIA. BIA fala: "Faz vocêtambém!". Nara continua olhando. BIA fala: "A areia está muito mole, tem que molhar". Lúcio fala com BIA enquanto mexe no cabelo dela. Ela se vira para Lúcio, fala e sorri. Nara volta a mexer nos objetos; BIA olha Nara. Nara pede algo a BIA, que responde: "Vou pegar". Levanta e afasta-se, falando com Lúcio. Nara fica sozinha brincando com areia. BIA volta com um balde de água e diz: "Aqui, Nara, água". Nara olha, BIA afasta-se e volta-se para outras crianças.

\section{Sexto trecho}

Ângelo (1.6) - Creche privada

BIA conversa com as crianças. Ângelo olha, de vez em quando, na direção de BIA e das crianças. BIA e algumas crianças estão "planejando" uma festa de casamento. Ângelo observa os "preparativos". 
Ângelo pega uma lanterna e a põe no olho (como uma luneta). BIA olha Ângelo, sorri e diz: "Aí, Gel!" Ângelo tira a lanterna do olho e sorri para BIA. Ela: "Você sabe o que é isso? Uma lanterna, só que está quebrada". Ângelo mexe na lanterna. BIA fala com outras crianças.

No primeiro trecho, a educadora está sentada na borda no canteiro de areia, olhando e falando com Nara, dando-lhe suporte para o brinquedo. Enquanto isso, Lúcio está em cima do canteiro de areia, de pé, nas costas de BIA, mexendo no cabelo dela. BIA alterna sua atenção entre Nara e Lúcio, mas os temas da intervenção não estão conectados de qualquer forma. No segundo trecho, observa-se a repetição do padrão. Durante a conversa com um pequeno grupo, BIA faz uma pausa e entra em contato com Ângelo, estabelecendo-se o tópico de troca a partir da atividade de Ângelo, por sua vez, independente da atividade das outras crianças.

Comunicação articulada, com alternação de alvos e articulação entre os vários alvos

A terceira estratégia de contato empregada, bastante comum, é a comunicação com vários indivíduos, com alternação de alvos e articulação entre eles. Como se pode ver no segundo trecho, nas partes sublinhadas, a educadora muda de foco de uma para outra criança. Nas duas primeiras partes sublinhadas, a única mudança é o foco (de Mira para Breno André na primeira parte; de Breno André para Mira — na segunda), enquanto, na terceira parte, tanto há mudança de foco (de Mira para Breno Santos e depois para Breno André) como mudança de tópico, embora com temática articulada (de tomar café numa xícara para pôr a mão na boca, ao tossir), sendo a articulação dada pela dimensão "modo correto de fazer as coisas", de se portar em público, boas maneiras, etc.

De modo geral, essa parece ser uma estratégia central na situação de creche, empregada, evidentemente, de modo não consciente pelo adulto, porque as interações com uma criança se estendem para outra, ampliando a intervenção do adulto. Como se verá mais adiante, a criança tem um papel essencial nesse processo.

Qual o papel de cada uma dessas estratégias no contexto da creche e como elas se articulam? Assim como a comunicação diádica é a estratégia modal de contato no contexto familiar, entre mãe e criança, a estratégia de comunicação coletiva, por oposição, poderia corresponder ao padrão básico de contato entre adulto e criança na situação coletiva da creche. De fato, não há evidências de que seja esse o caso. Ao contrário, os exemplos desse tipo de comunicação não são muito freqüentes. $\bigcirc$ contexto em que aparecem, quase sempre, é o da necessidade de coordenar uma ação que deve ser realizada por todos, no mesmo momento, geralmente ordem, chamamento, mudança de rotina para todos. Por outro lado, a comunicação individual parece ocorrer mais em situações em que uma criança em particular afasta-se, em qualquer sentido, da tendência central do grupo, seja por isolamento, choro e outras mostras de infelicidade ou dificuldades, seja por comportamento considerado inade- 
quado. Quanto à comunicação "com vários indivíduos, com alternação de alvos e articulação entre eles" apareceu, em geral, em contextos de atividade com participação do adulto, em brincadeiras estruturadas, ou como no exemplo do Trecho 2, em que o adulto e as crianças comentam as gravuras.

Essas especificidades sugerem que o emprego de um ou outro tipo de estratégia de comunicação pode estar relacionado mais ao modo como a creche concebe e estrutura o papel do adulto do que à própria natureza do contexto. Se o adulto é visto como um guardião da disciplina do grupo, ele, provavelmente, tenderá a dirigir-se mais ao grupo do que a indivíduos isolados, o contrário do que seria provável se fosse esperado que ele se comportasse como um fornecedor de conforto e carinho. Se, por outro lado, acredita-se que é tarefa do adulto apoiar e organizar o brinquedo do grupo, inclusive dando suporte à participação de todas as crianças, é previsível que sejam empregadas as estratégias "mistas" de comunicação (grupo, com individualização). Em qualquer caso, não deve ser a natureza coletiva do contexto o único fator a afetar a maior ou menor presença de cada uma dessas modalidades.

\section{Estratégias da criança}

Aqui pretende-se demonstrar que a criança responde a essas diferentes estratégias empregadas pelo adulto de modo não linear, não pontual. A direção da atenção da criança não corresponde pontualmente à origem e natureza do contato. Propõe-se demonstrar que a direção das respostas ou iniciativas de interação da criança não corresponde necessariamente à origem das interações (adulto ou criança), e às estratégias utilizadas em cada caso (grupal, poliádica ou individual).

Observem-se os excertos 2 e 3 do segundo trecho, reproduzidos abaixo:

\section{Excerto 2}

SÍLVIA, de cabeça baixa, sem olhar para qualquer criança em particular, pergunta: "E aqui em cima, o que é?". Lino, na extremidade da mesa, distante um pouco de SÍLVIA, responde: "É areia, é areia, é areia!" SÍLVIA olha Lino, sorri, com as sobrancelhas arqueadas e diz: "Éee!". Mira diz, olhando Lino: "Areia". SÍLVIA olha Mira e diz: "É areia".

\section{Excerto 3}

Breno Santos (2. I0) começa a tossir. SílVIA mostra que se deve pôr a mão na boca. Breno Santos tosse, pondo a mão na boca. SílVIA põe a mão na frente da boca. Breno André (2.4) faz o mesmo. SÍLVIA olha Breno André, mantendo a mão sobre a boca, balança a cabeça confirmando. Mira (2.7) observa, olha alternadamente para Breno Santos e SÍLVIA, também põe a mão na frente da boca, da mesma forma que a professora, e tosse, olhando SÍLVIA.

No Excerto 2, uma comunicação do adulto, dirigida ao grupo, regula o comportamento de Lino e este, por sua vez, regula o comportamento da outra criança (Mira). Nesse 
caso, a interação do adulto com Lino é seguida por uma interação entre as duas crianças e, em seguida, pela reentrada do adulto no fluxo interativo.

No Excerto 3, a comunicação da educadora está focalizada em Breno Santos e, num segundo momento, em Breno André. Mira acompanha a interação entre Breno Santos e SÍLVIA, e responde apropriadamente ao conteúdo da interação, como se ela própria fosse o alvo da comunicação da educadora. Neste caso, uma interação da educadora com uma criança (Breno André) regula o comportamento de outra (Mira).

Assim, do mesmo modo que o adulto articula a interação num grupo, incluindo várias crianças no mesmo tópico ou ampliando o tópico, a criança articula sua interação com o adulto e com as demais crianças, incluindo-se no fluxo de interação do grupo e contribuindo para o desenvolvimento do conjunto do episódio interativo.

Por exemplo, no segundo trecho, SÍlVIA aponta a gravura e fala " Uma vaca!", dirigindo-se a Breno André. Em seguida, Mira olha a mesma gravura e repete "Uma vaca", o que é confirmado por SíLVIA. A enunciação do nome pela criança e a confirmação por SíLVIA é repetida em seguida com Júlia e, bem mais tarde, novamente com Breno André. Isso sugere que uma interação ocorrida entre um adulto e uma criança pode regular, e freqüentemente o faz, o comportamento das demais, num efeito em cadeia. Nesse processo, não se deve esperar que os agentes funcionem como "correias de transmissão" do fluxo interativo. Cada participante modifica o fluxo interativo, selecionando partes do conjunto, ampliando o conteúdo do tópico, modificando-o, rejeitando-o em favor de outras propostas.

Por exemplo, na sessão transcrita no segundo trecho (incluindo partes suprimidas neste texto), são mencionados como tópicos da interação, por ordem de aparecimento: parque, vaca, burro, jegue, onça, cavalo, homem, areia, menina, comportamento à mesa, fotografia, bicho, sapato e piolho. A maioria desses temas originou-se das gravuras que estavam sendo observadas, mas o maior ou menor desenvolvimento é dado pela contribuição diferencial dos participantes. Aqui o adulto parece ter um papel importante em estender e explorar múltiplos aspectos do tópico, mas é possível que o adulto apenas siga o curso do interesse e do engajamento da criança no tópico.

Ainda como ilustração, observe-se o episódio da brincadeira de rodar a bola, em que uma atividade é deixada de lado em favor de outra, descrita no Quarto trecho. Desde o começo da sessão, Nara está sentada na "roda", participando minimamente da atividade. $\bigcirc$ fato de afastar a bola de si, de ficar todo o tempo com expressão desinteressada, pode ter contribuído para o encerramento da brincadeira. Em seguida, a educadora sugere uma atividade (esconde-esconde) e dá um comando para o início da brincadeira. Nara, porém, apresenta outra sugestão (brincadeira de cabaninha), imediatamente aceita por BIA e pelas crianças e que, embora demorando um tempo até ser concretizada, alcança um alto grau de envolvimento de muitas crianças.

Em síntese, a apresentação desses exemplos ilustra o argumento básico de que a situação de creche ultrapassa em muitos sentidos o caráter de situação coletiva ou de rela- 
ções adulto criança na proporção determinada pelo número de crianças por adulto. Nem o adulto lida com as crianças como um conjunto indistinto ou com uma criança de cada vez, nem a criança se relaciona com adulto e outra criança como pontos isolados.

Em vez disso, o fluxo interativo mostra-se como um processo em que os participantes todos influenciam uns aos outros, de modo articulado e dinâmico. Não só o adulto envolve-se em episódios complexos de construção de conhecimento, como seu envolvimento não se dá apenas com uma criança de cada vez. A proporção dessa estratégia entre as diversas possíveis não está ainda esclarecida, mas sua viabilidade é fortemente sugerida quando se observam episódios de interação articulada entre o adulto e várias crianças, por longos períodos de tempo.

\section{DISCUSSÃO E CONCLUSÕES}

As análises precedentes permitem afirmar que o contexto de creche, em si, não é um obstáculo para uma troca social com o adulto e a outra criança, rica e complexa, em vista do emprego de estratégias apropriadas ao contexto. Essa conclusão é compatível, em geral, com uma grande variedade de estudos sobre os modos pelos quais os indivíduos ajustam-se aos contextos interativos em que estão envolvidos, alterando o seu próprio comportamento, de modo a torná-lo mais sintonizado com as características do parceiro de interação. Essas estratégias constituiriam o que Papousek, Papousek (1984) denominam competência de suporte ambiental, ou seja, o modo pelo qual os adultos ajustam o ambiente à competência da criança. Há dados provenientes de estudos em comunicação verbal sobre o babytalk ou motherese, em que adultos assumem automaticamente estilos de conversação diferentes dependendo do contexto interativo (Snow et al., 1976; Hoff-Ginsberg, 1991). Também a literatura sobre mecanismos que operam na formação do vínculo do apego revela a importância da sincronia na pareceria adulto criança na construção do sistema de apego.

Um dos aspectos mais relevantes evidenciado por essa literatura é o caráter não planejado e, freqüentemente, inconsciente, das mudanças de estilo adulto. Evidências recentes sobre esse fenômeno podem ser encontradas num estudo de Haden e Fivush (1996). Esses autores constataram que as mães variam seus estilos de conversação com suas crianças de cerca de três anos, de acordo com diferentes contextos interacionais: as médias de itens como pedidos, confirmações, clarificações, diretivas e negações diferiram significativamente conforme o contexto interativo fosse uma situação de brinquedo livre ou uma conversa sobre eventos passados. Também um estudo de Lewis et al., 1996, sobre diferenças entre estilos de interação de pais e mães em diferentes contextos apontou diferenças e semelhanças nos estilos observados: tanto o pai quanto a mãe simplificam o seu modo de comunicação em situações de interação com suas crianças e ajustam suas estratégias de acordo com a contexto de interação, embora com um efeito moderador do sexo do genitor e da criança. Essa flexibilidade estende-se, aparentemente, às próprias crianças, que se mostram capazes de reconhecer mudanças de status do parceiro e adaptar seu comportamento ao tipo de 
parceiro ou à circunstância do contexto (Shatz, Gelman, 1973; Dunn, Kendrick, 1981; Lordelo, 1986; Marcos, 1995).

Os dados deste estudo podem ter um alcance limitado à situação de creche, tendo em vista o grande número de crianças por adulto e as numerosas tarefas que este último deve desempenhar numa creche, as quais concorrem com a atenção direta à criança. Também é possível que as variações na organização das creches, em termos de razão adulto criança, tamanho dos grupos, estruturação espacial, políticas pedagógicas adotadas, entre outras características, possam influenciar a disponibilidade do adulto em interagir com a criança e as direções em que essas interações são mais prováveis, como evidenciado nos estudos de Smith e Conolly (1980), Rubiano (1990), Campos de Carvalho (1990). O que a literatura sugere, entretanto, é uma ampla capacidade do comportamento humano em ajustar-se ao contexto. Considerar as possibilidades da creche como contexto de desenvolvimento requer que se leve em conta essa marcante característica humana, que desautoriza a comparação linear de contextos interativos diádicos e poliádicos. Em outras palavras, se uma criança é exposta a uma razão adulto criança de 1 : 10 , isso absolutamente não significa que ela receberá um décimo da atenção que lhe caberia se estivesse sendo criada com a mãe em casa. $\bigcirc$ comportamento, tanto dos adultos quanto das crianças, ajusta-se aos diferentes contextos.

Assim, os dados deste estudo, em conjunto com as evidências em literatura, sugerem uma inerente flexibilidade dos parceiros sociais para ajustamento a diferenças contextuais. A generalidade dessa proposição à situação da creche, entretanto, requer mais investigação, tendo em vista a grande variabilidade existente nas creches, em termos de ambiente físico, recursos, políticas educacionais e estilos pessoais, variáveis que devem ter efeitos no fenômeno.

Torna-se importante, assim, o exame cuidadoso das variações que são observadas em cada creche e as possíveis associações entre essas variações e a troca social. Desse modo, será possível avançar do conhecimento sobre trocas sociais em tese, para um conhecimento sobre essas possibilidades em situações concretas, especificando as variações nas condições consideradas relevantes para o problema. Aspectos como estruturação do espaço físico e social, currículos, recursos, concepções sociais sobre a creche, entre outros, podem estar envolvidos no modo como adulto e criança estruturam suas relações.

A pesquisa sobre interação social e desenvolvimento tem evidenciado a precoce capacidade da criança para interagir, inclusive com outras crianças, com um forte componente motivacional (Carvalho, Beraldo, 1989; Pedrosa, Carvalho, 1995). Por outro lado, a realidade da criação em situação de creche, as sugestões da literatura sobre ausência de efeitos apreciáveis da experiência de creche em muitos dos aspectos da vida da criança, impõem um redirecionamento da pesquisa para a elucidação dos mecanismos que operam nesses resultados. Como a criança lida com a situação de creche? Como os adultos se ajustam a diferentes contextos de cuidado? Como os currículos das creches (explícitos e implícitos) são integrados às possibilidades dos sujeitos envolvidos? Estas são algumas das questões que podem 
ser divisadas a partir desta pesquisa, como tópicos promissores de investigação futura e com amplas implicações práticas.

\section{REFERÊNCIAS BIBLIOGRÁFICAS}

BELSKY, J., GOODE, M.K., MOST, R.K. Maternal stimulation and infant exploratory competence: Cross-sectional, correlational, and experimental analyses. Child Development, n.51, p.1 163-78, 1980.

BERGAMASCO, N.H.P. Facial expressions as communicative acts in neonates. In: CONFERENCE OF DEVELOPMENTAL: PSYCHOLOGY. Abstracts of European. Sevilha: ISSBD, 1992. p. 243.

BOWLBY, J. Apego. São Paulo: Martins Fontes, 1984.

CARVALHO, A.M.A., BERALDO, K.E.A. Interação criança-criança: ressurgimento de uma área de pesquisa e suas perspectivas. Cadernos de Pesquisa, n.7I , p.55-6I , nov. 1989.

CARVALHO, M.I.C. Arranjo espaciale distribuição de crianças de 2-3 anos pela área de atividades livres em creches. São Paulo, 1990. Tese (Dout.) IP-USP.

DUNN, J., KENDRICK, C. The Speech of two and three-years-old to infant sibling: "babytalk" and the context of communication. Journal of Child Language, n.9, p.579-95, I 981 .

FREUND, L.S. Maternal regulation of children's problem-solving behavior and its impact on children's performance. Child Development, v.6I, n. I, p. I 13-26, 1990.

HADEN, C. A., FIVUSH, R. Contextual variation in maternal conversational styles. MerrilPalmer Quarterly, v.42, n.2, p.200-27, 1996.

HOFF-GINSBERG, E. Mother-child conversation in different social classes and communicative settings. Child Development, n.62, p.782-96, 1991.

ISABELLA, R.A., BELSKY, J. Interactional synchrony and the origins of infant-mother attachment: a replication study. Child Development, n.62, p.373-84, 1991.

KONNER, M.J. Relations among infants and juveniles in comparative perspective. Socia/ Science Information, n. I5, p.37I-402, 1976.

LANDRY, S.H. et al. Effects of maternal scaffolding during joint toy play with preterm and fullterm infants. Merril-Palmer Quarterly, v.42, n.2, p. 177-99, 1996.

LEWIS, C. et al. Observer influences on fathers and mothers: an experimental manipulation of the structure and function of parent-infant conversation. Early Developmental and Parenting, v.5, n. I, p.57-68, 1996.

LORDELO, E.R. Comportamento de cuidado entre crianças. São Paulo, 1986. Dissert. (mestr.)IP-USP. 
MARCOS, H. Mother-child and father-child communication in the second year: a functional approach. Early Developmental and Parenting, v.4, n.2, p.49-61, 1995.

OLIVEIRA, Z.M.R., FERREIRA, M.C.R. Propostas para o atendimento em creches no município de São Paulo: histórico de uma realidade. Cadernos de Pesquisa, n.56, p.3965, fev. 1986.

PAPOUSEK, H., PAPOUSEK, M. Learning and cognitive in the everyday life of human infants. Advances in the Study of Behavior, v. 14, p. 127-59, 1984.

PEDERSON, D. et al. Maternal sensitivity and the security of infant-mother attachment: a qsort study. Child Development, n.6I, p.1974-983, 1990.

PEDROSA, M.C.I.P., CARVALHO, A.M.A. ( 1995). A interação social e a construção da brincadeira. Cadernos de Pesquisa, n.93, p.60-5, maio 1995.

ROSEMBERG, F. Creche. São Paulo: Cortez, 1989.

ROSEMBERG, F., CAMPOS, M.M. Creches e pré-escolas no hemisfério norte. São Paulo: Cortez; Fundação Carlos Chagas, 1994.

ROSSETI-FERREIRA, M.C. O Contexto de educação da criança pequena segundo a psicologia do desenvolvimento: um debate internacional. São Paulo, 1995. [Comunicação à $X X V^{a}$ Reunião Anual da Sociedade Brasileira de Psicologia.]

. Organizando o meio para o desenvolvimento de interações em creches. Caderno de Desenvolvimento Infantil, v. I, n. I, p.8-10, 1994.

RUBIANO, M.R.B.(1990). Suportes ambientais e organização social de crianças em creche. São Paulo, 1990. Tese (dout.). IP-USP.

SCARR, S. e EISENBERG, M. Child care research: issues, perspectives, and results. Annual Review of Psychology, n.44, p.613-44, 1993.

SCHAFFER, H.R. Joint involvement episodes as context for development. In: McGURK, H. (ed.). Childhood social development. contemporary perspectives. Hove: Lawrence Erlbaum Associates, 1992.

SEINER, S.H., GELFAND, D.M. Effects of mothers' simulated withdrawal and depressed affect on mother-toddler interactions. Child Development, n.66, p. I 5 I9-28, 1995.

SHATZ, M., GELMAN, R. The Development of the communication skills: modifications in the speech of young children as a functions of listener. Monographs of the Society for Research in Child Development. v.38 (n.5, Série I52), 1973.

SLADE, A. A Longitudinal study of maternal involvement and symbolic play during the toddler period. Child Development, n.58, p.367-75, 1987. 
SMITH, P.K., CONNOLLY, K.J. The Ecology of preschool behaviour. Cambridge: Cambridge University Press, 1980.

SNOW, C.E. et al. Mothers'speech in three social classes. Journal of Psycholinguistic Research, n.5, p.I-20, 1976.

WEININGER, O. Play of mothers with babies: some relationships between maternal personality and early attachment and development processes. Psychological Reports, n.53, p.2742, 1983. 